\title{
Comparative evaluation of the microbial leakage at two different implant-abutment interfaces using a new sealant
}

\author{
Sri Kavya Jyothsna Akula, Hariharan Ramakrishnan, Azhagarasan Nagarasampatti Sivaprakasam \\ Department of Prosthodontics \& Implantology, Ragas Dental College \& Hospital, The TN Dr MGR Medical University, Chennai,
} India

Purpose: To evaluate the microbial leakage at two different implant-abutment interfaces using a new sealant.

\begin{abstract}
Materials and Methods: Forty implants of the size 4.2 Dx11.5 L (Adin, Israel), internal hex, were selected. Twenty titanium abutments (Adin, Israel) with twenty titanium implants were used in Group 1, twenty CAD/CAM zirconia abutments with twenty titanium implants were used in Group 2. Each group was subdivided into two subgroups, subgroup A-control without sealant and subgroup B- with the new sealant. Implants were immersed in a brain heart infusion broth (Accumix Microxpress, India), and a polymicrobial solution (ATCC 10556 Streptococcus sanguis, Himedia, India, and ATCC 90030 Candida glabrata Himedia, India) was introduced into the Eppendorf tubes (Tarson, India) containing the implant assemblies of the four subgroups and incubated for 14 days. Then samples from the implant wells were taken using sterile absorbent paper points (Diadent, Korea) and cultured in Mueller Hinton agar (Himedia India). The colonies formed were counted using a digital colony counter. The results obtained were tabulated and statistically analyzed.
\end{abstract}

Results: The Mann-Whitney $U$ test was used to compare the values between the two groups. There was a significant difference in the microbial leakage in the titanium abutments with and without the new sealant for both microorganisms $(\mathrm{P}<0.05)$. There was also a significant difference in microbial leakage in the zirconia abutments with and without the new sealant for both microorganisms $(P<0.05)$. There was no statistically significant difference in the microbial leakage between titanium and zirconia abutments treated with the new sealant for both the microorganisms $(P>0.05)$.

Conclusions: There was a significant reduction in microbial leakage for both microorganisms on the application of the new sealant in both the titanium and zirconia abutments over titanium implants. The new sealant used has both antibacterial and antifungal efficacy on usage with both types of abutments over titanium implants. (JOURNAL OF DENTAL IMPLANT RESEARCH 2021;40(2):35-47)

Key Words: Dental implants, Dental implant abutment design, Dental leakage, Microbiology, Titanium, Zirconia

\section{INTRODUCTION}

Titanium is the ideal material in implant dentistry due to its excellent biocompatibility. However in cases with thin gingival biotype, usage of Titanium causes greyish hue to surrounding soft tissues affecting the esthetic outcome, Zirconia abutments are preferred in such cases ${ }^{1-3}$. In contrast to Titanium abutments, Zirconia abutments have natural tooth like color, high translucency, excep- tional tissue-compatibility and fracture strength ${ }^{4)}$. Early adhesion/colonization of bacteria on Zirconia surfaces was significantly less compared to Titanium, which proves that Zirconia and its derivatives have the capacity to reduce plaque on implant and tissues, favouring better soft tissue healing and implant success at bone level ${ }^{5-7)}$.

Zirconia abutments enhance peri -implant bone health by reducing inflammation and less bleeding on probing as compared to Titanium abutment ${ }^{1)}$. Despite the high

Received March 14, 2021, Revised April 19, 2021, Accepted April 22, 2021.

(c) Journal of Dental Implant Research.

This is an open access article distributed under the terms of the Creative Commons Attribution Non-Commercial License

(http://creativecommons.org/licenses/by-nc/4.0) which permits unrestricted non-commercial use, distribution, and reproduction in any medium, provided the original work is properly cited.

Correspondence to: Hariharan Ramakrishnan, https://orcid.org/0000-0003-4466-5744

Department of Prosthodontics \& Implantology, Ragas Dental College \& Hospital, Uthandi, Chennai 600119, India. Tel: +91-44-24530006, Fax: +91-44-52123995, E-mail: abcv2005@yahoo.com 
success rates for dental implant-supported prosthesis,peri-implant pathology exists and a thorough knowledge regarding it is not available. The presence of a microgap between implant fixture and abutment might be a possible etiological factor ${ }^{8-11)}$.

Definition of Microgap is given as the microspace that exists between the implant fixture and abutment. This gap is located at the alveolar crest level and is generally in microns ${ }^{8,10)}$. This microgap acts as a reservoir for microorganisms which leads to release of by products and may induce inflammatory reaction in both soft and hard tissues around the implants ${ }^{10,12-15)}$.

The microgap of the Titanium-to-Titanium interface has been widely documented in terms of precision of fit, whereas the Zirconia-to-Titanium interface has not been well documented in the scientific literature. The size of the microgap is influenced by factors like the precision of the milling method and the correct torque of the screw that joins the two pieces (implant and abutment) together and implant connection designs.

All connection designs between the implant and its respective abutment may be classified in two different types: external connections and internal connections. These differ in many ways, including surface and precision of $\mathrm{fit}^{16)}$. In two-stage implants microgap is present near the crestal bone whereas in one-stage implants the microgap between the abutment and the implant is near the gingival crest ${ }^{17)}$.

Lack of precise fit at the implant abutment interface near the crestal bone may result in marginal microgap causing microleakage that will lead to inflammation and bone loss ${ }^{17-20)}$.

Micromotion in apparently stable implant screw joints is because of loading clinically. This micromotion may contribute to screw loosening and prosthesis failure.Thus, the more precise the fit, the less micromotion will occur, there by enhancing the longevity of the prosthesis ${ }^{17}$.

Several in vitro and in vivo studies have evaluated the ability of different species of microorganisms to penetrate into the IAI with different types of abutments and different types of implant geometry ${ }^{10,12,14,21-23)}$.

The ability of Streptococcus sanguinis to penetrate into and along the implant abutment fixture was proved by Quirynen and Von Steenberg in 1993 in their in vivo study ${ }^{8)}$. Streptococcus sanguinis is a small size gram-positive coccus, measuring between 0.5 and $1 \mu \mathrm{m}$, and a commonly found organism in the biofilm formed on the implants ${ }^{12,13,24)}$. Streptococci strains are reported to have the unique ability to bind to other microbial species (coaggregation) and to each other (aggregation) ${ }^{12,25)}$.

These bacteria are frequently associated with Candidal organism, a commensal fungal species often found in biofilms of peri-implant areas that infect mucosal and gum tissues only when the host defenses are weak ${ }^{12,25)}$.

Candida species are an important resident microbial organism of the oral microbiome. In the formation of biofilm on implantable medical devices including dental implants these organisms are frequently seen. The artificial materials introduced into the body are accompanied by the ability of microorganisms, including Candida species, to colonize them and form biofilms ${ }^{25)}$. This biofilm protect them from antibiotic diffusion and host defenses, leading to persistent infections ${ }^{12}$. Candida glabrata represents an emerging species of nonalbicans Candida and is a smal fungi $(2.0 \sim 4.03 \times 3.0 \sim 5.5 \mu \mathrm{m}$ in size) is a common organism in the oral cavity and is known for its ability to colonize medical devices ${ }^{12}$. There are very limited number of studies in which the ability of fungi in coaggregation to Streptococci sanguinis to colonize the implant abutment interface microgap had been studied.

Many methods for analysis of microbial leakage like nutrient medium turbidity, DNA checkerboard, Real time Quantitative reverse transcription polymerase chain reaction (q RTPCR), gram-staining, biochemical reactions, colony forming units are employed in different studies ${ }^{26)}$. The widely used gold standard method is Colony Forming Units (CFU) counting on plates.

In this study we have counted the colony forming units using digital colony counter for both Streptococcus sanguinis and Candida glabrata. Only viable bacteria are counted in this particular method, which excludes dead bacteria and debris and any number of bacteria using dilution can be counted ${ }^{27}$. Numerous efforts were put in, to seal the microgap between the implant and the abutment for preventing microleakage at the implant-abutment interface. Several materials have been used to seal the implant - abutment interface, such as, adhesive, silicone $\mathrm{O}$ - ring, a silicon hermetic washer, chlorhex- 


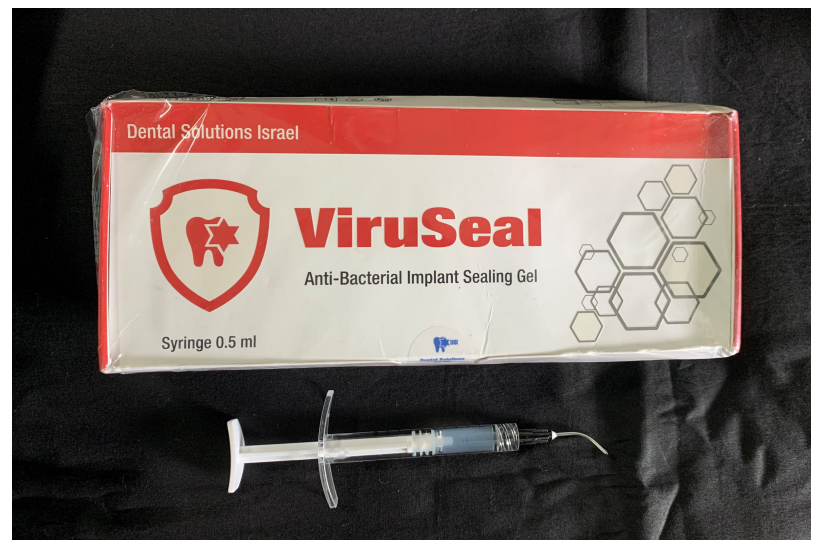

Fig. 1. Viruseal antibacterial sealant (DSI, Israel).

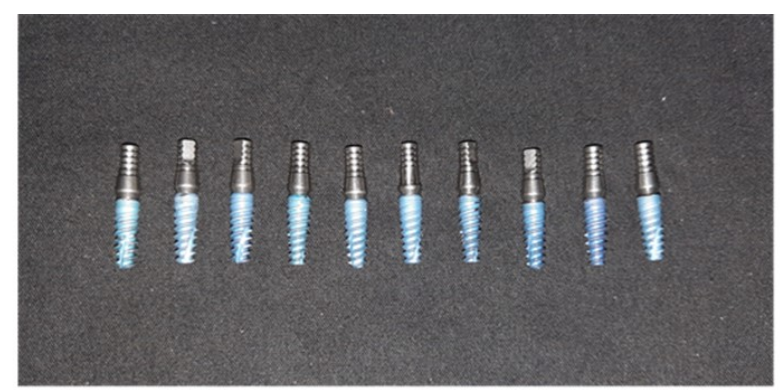

Fig. 2. Subgroup $1 \mathrm{~A}(\mathrm{n}=10)$-Titanium abutments-Titanium implants-control-unsealed.

idine-thymol varnish, and $2 \%$ chlorhexidine solution, some commercial antiseptic sealents like Gapseal, Keiroseal are also available 28-33) $^{2}$

In this study a new antiseptic sealent Viruseal (Polydimethysiloxane, Aerosol 380, Thymol, DSI, Israel) has been used ${ }^{34)}$, with both Titanium and Zirconia abutments connected to internal hexagon type of connection of Titanium implants. Currently, there is very limited data available on possible microleakage problems related to CAD/CAM milled Zirconia abutments after application of a sealant.

The aim of this study was to determine the microbial leakage of 2 different types of organisms (Streptococcus sanguinis, Candida glabrata) in 2 groups of implants with different abutments.

Null-hypothesis adopted for this study was that there will be no differences between stock Titanium abutments and CAD/CAM Zirconia abutments in preventing microbial leakage at implant abutment interface after application of a new antiseptic sealant.

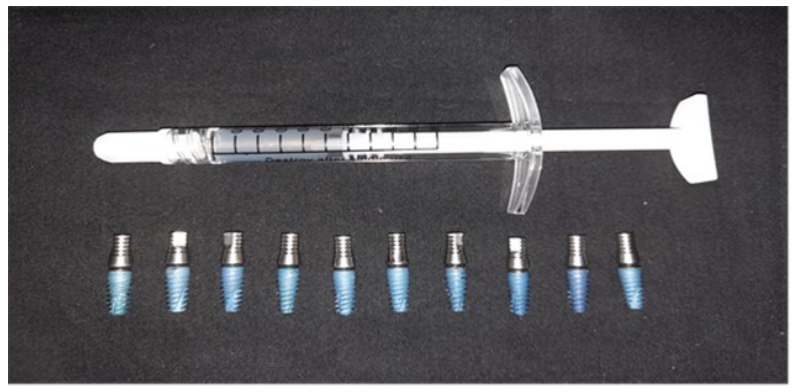

Fig. 3. Subgroup $1 B(n=10)$-Titanium abutment-Titanium implantSealant applied at IAI.

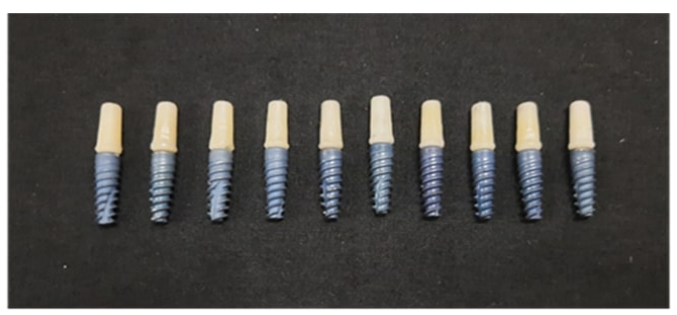

Fig. 4. Subgroup $2 A$ ( $n=10)-C A D / C A M$ Zirconia abutment-Titanium implants-control-unsealed.

\section{MATERIALS AND METHODS}

\section{Methodology}

Forty premachined Titanium implants and twenty Titanium abutments (Adin, Israel) were purchased. Preparation of another twenty Zirconia abutments with Zirconia blocks were carried out. Standard platform straight CAD/CAM milled twenty Zirconia abutments were fabricated using EXOCAD software for designing, and WorkNC Software for milling Zirconia blocks (DG STAR, Unbreakable solid zirconia, DENTGALLOP USA) using Yenadent, 5 AXIS CAD/CAM milling machine and sintered using Vita ZYRCOMAT 6000 MS Sintering machine. Fit of these forty abutments were checked on to the implants. Autoclave (Unident Imported Sun B Class Autoclave, Hyvin Care, New Delhi) was used to sterilize the implants and abutments to ensure that they are not contaminated (121C- 20 minutes, at $15 \mathrm{lb}$ pressure).

The new sealant (Fig. 1) used in this study was applied on top of twenty implants. Ten Titanium abutments and ten Zirconia abutments were torqued to manufactures recommended torque value $(35 \mathrm{Ncm})$ using hexdriver and torque wrench without application of sealant. Ten Titanium abutments and ten Zirconia abutments were 


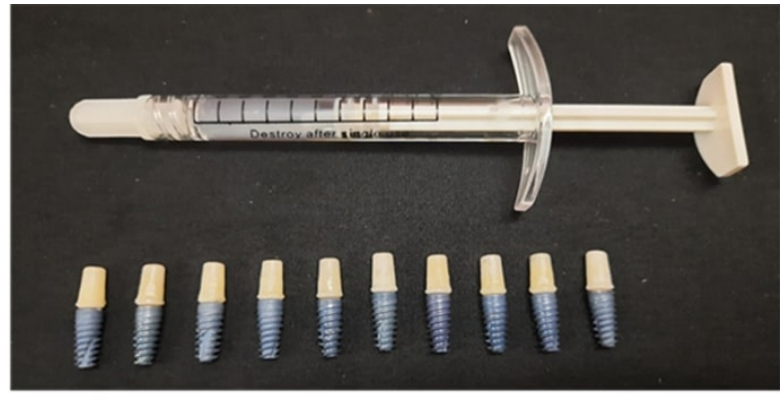

Fig. 5. Subgroup 2B-Zirconia abutments-Titanium implants-Sealant applied at IAI.

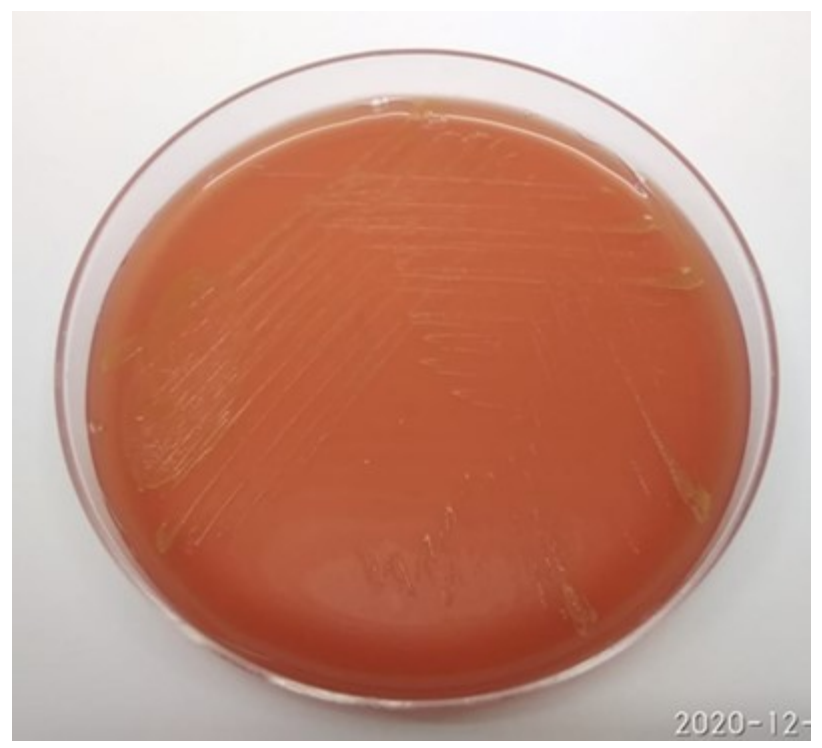

Fig. 6. ATCC 10556 Streptococcus sanguinis (Himedia, Mumbai, India).

torqued to manufactures recommended torque value (35 $\mathrm{Ncm}$ ) using hexdriver and torque wrench after the application of sealant on top of implants. Forty Titanium implants were divided into 2 groups of twenty each (Group 1 and Group 2), in which GROUP 1 were divided into 2 subgroups based on the application of sealant. SUBGROUP 1A (control-Unsealed) (Fig. 2) and SUBGROUP 1B (VIRUSEAL applied) (Fig. 3). GROUP 2 were divided into 2 Subgroups based on the application of sealant SUBGROUP 2A (Control-unsealed) (Fig. 4) and SUBGROUP 2B (VIRUSEAL applied) (Fig. 5). The test bacterial strain, ATCC 10556 Streptococcus sanguinis (Fig. 6) and fungi ATCC 90030 Candida glabrata (Fig. 7) (Himedia, Mumbai) were revived from glycerol stock maintained at $-20^{\circ} \mathrm{C}$. The overnight young subculture of the both test strains were suspended in $2 \mathrm{ml}$ Brain heart

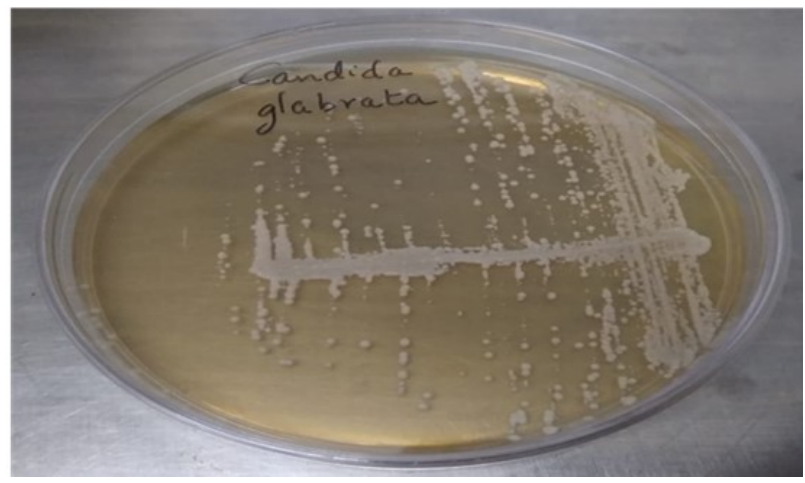

Fig. 7. ATCC 90030 Candida glabrata (Himedia, Mumbai, India).

infusion broth (BHIB) (Himedia, Mumbai) for preparing the polymicrobial broth suspension.

Thirty seven grams of Brain heart infusion broth powder was suspended in one litre of distilled water and mixed well. The prepared Brain heart infusion broth was autoclaved at $15 \mathrm{lb}$ pressure, $121^{\circ}$ centigrade for 15 minutes. Both Group I (twenty Titanium- Titanium abutment implants) and Group II (twenty Zirconia abutment-Titanium implants) assemblies were immersed in fresh Brain heart infusion broth, a little above the implant abutment interface in forty eppendorf tubes individually to avoid contamination through the access holes, under the Laminar air flow chamber to maintain the aseptic condition. The implant abutment assemblies in the forty eppendorf tubes were inoculated with $2 \mu$ polymicrobial suspension at the end of the tubes (Fig. 8), into the Brain heart infusion broth. All the assemblies were incubated in Ausco selec 3303 incubator (Ashok United Scientific co, TAMIL NADU) at $37^{\circ} \mathrm{C}$ for 14 days with intermittent BHIB refreshment for every $48 \mathrm{hrs}$ for maintaining the viability of the organism.

After the incubation period of 14 days all the implant assemblies were removed from polymicrobial suspension and were subjected to thorough rinsing with diluted $1 \%$ sodium hypochlorite followed by saline wash to avoid contamination from the surface of implant fixtures to implant wells. The Zirconia and Titanium abutments were detorqued using Adin hex drive from the implants aseptically under the laminar air flow chamber. Sample collection was done by insertion of absorbent paper points (DIADENT, Korea) from the implant wells. The samples taken from the implant wells were plated using Spread 

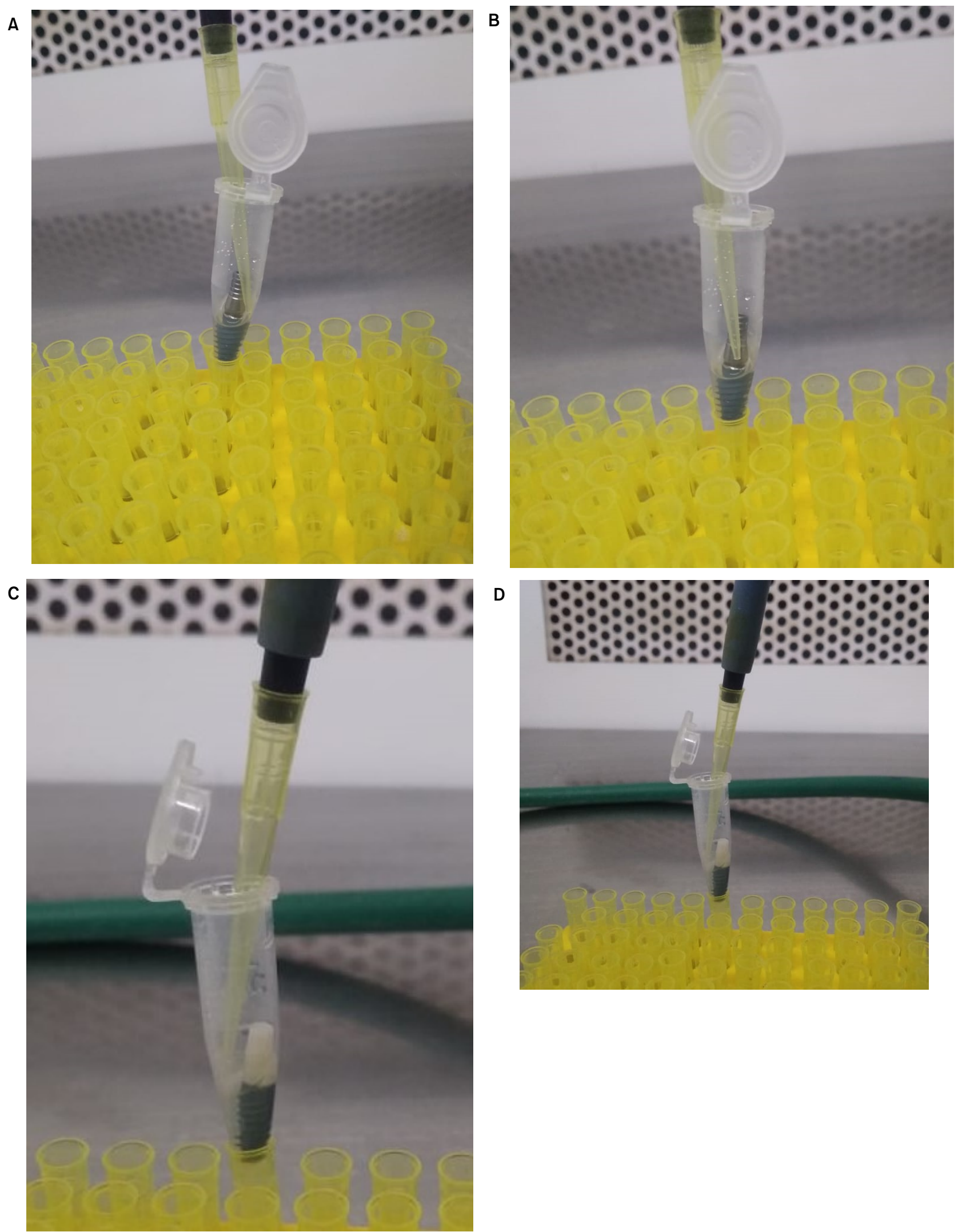

Fig. 8. Polymicrobial inoculation (A) Subgroup 1A. (B) Subgroup 1B. (C) Subgroup 2A. (D) Subgroup 2B. 
plate - pure culture technique on MUELLER HINTON AGAR and incubated for 24 hrs and organisms were differentiated based on colony morphology (Fig. 9, 10). The colonies were counted using a digital colony counter and the total colony forming unit was calculated using the formula:

Total colony forming unit, $\mathrm{CFU} / \mathrm{ml}=$

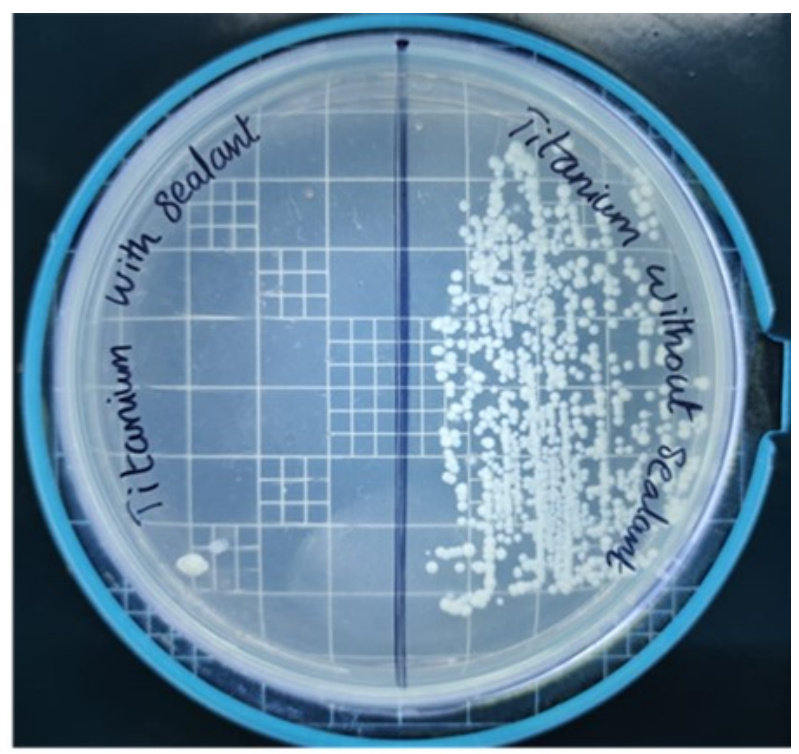

Fig. 9. Petri dish showing colony forming units in Titanium abutments with and without sealant using colony morphology.
Total number of colony counted/Dilution factor

The number of colonies formed were counted in all the four subgroups tabulated using Microsoft Excel 10 (Microsoft, USA) and median were calculated by taking the CFUS obtained from each group samples. The data were subjected to statistical analysis using SPSS software for windows 10.0.5 (SPSS Software Corp, Germany).

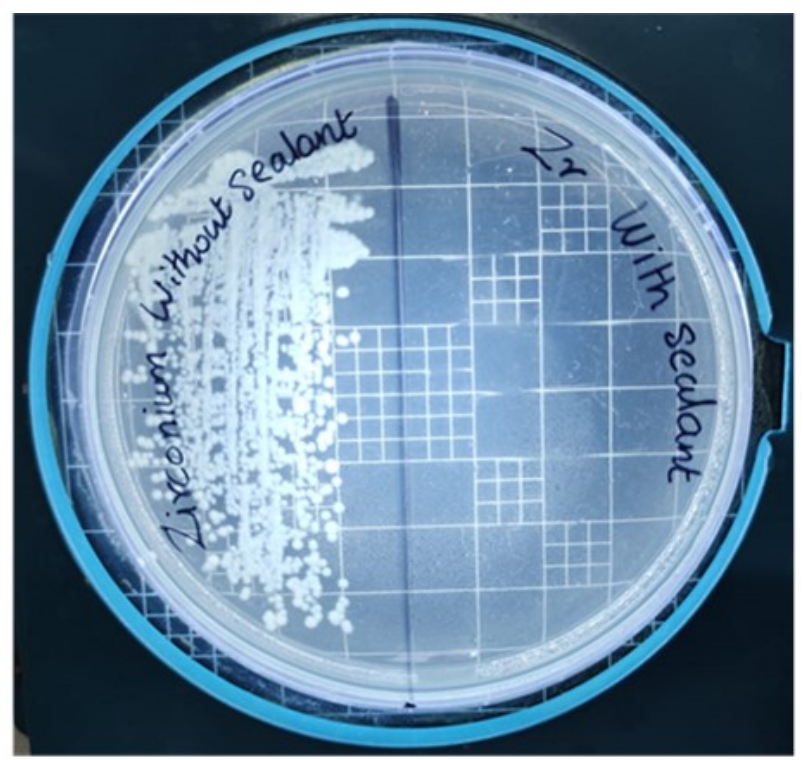

Fig. 10. Petri dish showing colony forming units for Zirconia abutments with and without sealant using colony morphology.

Table 1. To compare microleakage between (Titanium abutments) subgroup $1 \mathrm{~A}$ and $1 \mathrm{~B}$ for Streptococcus sanguinis with and without sealant

\begin{tabular}{ccc}
\hline & Subgroup 1AS (CFUs/ml) & Subgroup 1BS $(\mathrm{CFUs} / \mathrm{ml})$ \\
\hline Sample 1 & $10^{8}$ & $2 \times 10^{2}$ \\
Sample 2 & $10^{8}$ & Growth inhibited \\
Sample 3 & $10^{8}$ & Growth inhibited \\
Sample 4 & $10^{8}$ & Growth inhibited \\
Sample 5 & $10^{8}$ & $3 \times 10^{2}$ \\
Sample 6 & $10^{8}$ & Growth inhibited \\
Sample 7 & $10^{8}$ & Growth inhibited \\
Sample 8 & $10^{8}$ & Growth inhibited \\
Sample 9 & $10^{8}$ & Growth inhibited \\
Sample 10 & $10^{8}$ & Growth inhibited \\
\hline Organism tested & Group 1 & P-value \\
\hline Streptococcus sanguinis & "Without sealant (subgroup 1AS) & $0.002^{*}$ \\
Streptococcus sanguinis & "With sealant (subgroup 1BS) & Median \\
\hline
\end{tabular}

\footnotetext{
"Mann Whitney $U$ test to determine difference in microbial leakage for $S$. sanguinis between $1 \mathrm{AS}$ and $1 \mathrm{BS}$.

The cell density of the inoculated polymicrobial suspension is $10^{8} \mathrm{CFUs} / \mathrm{ml}$.

*P-value <0.05 considered significant.

Subgroup 1AS: Titanium abubments without sealant,checked for Streptococcus sanguinis.

Subgroup 1BS: Titanium abutments with sealant,checked for Streptococcus sanguinis.
} 
Table 2. Comparision of microbial leakage between subgroup $1 \mathrm{~A}$ and $1 \mathrm{~B}$ for Candida glabrata (Titanium abutments) with and without sealant

\begin{tabular}{|c|c|c|c|}
\hline & \multicolumn{2}{|c|}{ Subgroup 1AC (CFUs/ml) } & Subgroup 1BC (CFUs/ml) \\
\hline Sample 1 & \multicolumn{2}{|c|}{$10^{8}$} & Growth inhibited \\
\hline Sample 2 & \multicolumn{2}{|c|}{$10^{8}$} & Growth inhibited \\
\hline Sample 3 & \multicolumn{2}{|c|}{$10^{8}$} & Growth inhibited \\
\hline Sample 4 & \multicolumn{2}{|c|}{$10^{8}$} & Growth inhibited \\
\hline Sample 5 & \multicolumn{2}{|c|}{$10^{8}$} & Growth inhibited \\
\hline Sample 6 & \multicolumn{2}{|c|}{$10^{8}$} & Growth inhibited \\
\hline Sample 7 & \multicolumn{2}{|c|}{$10^{8}$} & $3 \times 10^{2}$ \\
\hline Sample 8 & \multicolumn{2}{|c|}{$10^{8}$} & Growth inhibited \\
\hline Sample 9 & \multicolumn{2}{|c|}{$10^{8}$} & Growth inhibited \\
\hline Sample 10 & \multicolumn{2}{|c|}{$10^{8}$} & Growth inhibited \\
\hline Organism tested & Group 1 & Median & P-value \\
\hline Candida glabrata & ${ }^{\#}$ Without sealant (subgroup $1 \mathrm{AC}$ ) & 8.0000 & $0.002 *$ \\
\hline Candida glabrata & "With sealant (subgroup 1BC) & 2.3010 & \\
\hline
\end{tabular}

\#Mann Whitney $U$ test to determine difference in microbial leakage for Candida glabrata between $1 \mathrm{AC}$ and $1 \mathrm{BC}$.

The cell density of the inoculated polymicrobial suspension is $10^{8} \mathrm{CFUs} / \mathrm{ml}$.

*P-value<0.05: Statistically significant.

Subgroup 1AC: Titanium abutments without sealant checked for Candida glabrata.

Subgroup 1BC: Titanium abutments with sealant checked for Candida glabrata.

Table 3. To compare microbial leakage between subgroup $2 \mathrm{~A}$ and $2 \mathrm{~B}$ for Streptococcus sanguis with and without sealant (Zirconia abutments)

\begin{tabular}{|c|c|c|c|}
\hline & \multicolumn{2}{|c|}{ Subgroup 2AS (CFUs/ml) } & Subgroup 2BS (CFUs/ml) \\
\hline Sample 1 & \multicolumn{2}{|c|}{$10^{8}$} & Growth inhibited \\
\hline Sample 2 & \multicolumn{2}{|c|}{$10^{8}$} & $2 \times 10^{2}$ \\
\hline Sample 3 & \multicolumn{2}{|c|}{$10^{8}$} & Growth inhibited \\
\hline Sample 4 & \multicolumn{2}{|c|}{$10^{8}$} & Growth inhibited \\
\hline Sample 5 & \multicolumn{2}{|c|}{$10^{8}$} & Growth inhibited \\
\hline Sample 6 & \multicolumn{2}{|c|}{$10^{8}$} & Growth inhibited \\
\hline Sample 7 & \multicolumn{2}{|c|}{$10^{8}$} & Growth inhibited \\
\hline Sample 8 & \multicolumn{2}{|c|}{$10^{8}$} & Growth inhibited \\
\hline Sample 9 & \multicolumn{2}{|c|}{$10^{8}$} & Growth inhibited \\
\hline Sample 10 & \multicolumn{2}{|c|}{$10^{8}$} & Growth inhibited \\
\hline Organism tested & Group 2 & Median & $p$-value \\
\hline Streptococcus. sanguinis & ${ }^{\#}$ Subgroup 2AS (without sealant) & 8.0000 & $0.002 *$ \\
\hline Streptococcus. sanguinis & "Subgroup 2BS (with sealant) & 2.3010 & \\
\hline
\end{tabular}

\#Mann Whitney $U$ test to determine difference in microbial leakage for Streptococcus sanguinis between 2AS and 2BS.

The cell density of the inoculated polymicrobial suspension is $10^{8} \mathrm{CFUs} / \mathrm{ml}$.

P-value<0.05: Statistically significant.

Subgroup 2AS: Zirconia abutments without sealant for Streptococcus sanguinis.

Subgroup 2BS: Zirconia abutments with sealant for Streptococcus sanguinis.

\section{RESULTS}

All the implants were immersed in brain heart infusion broth and a poly microbial solution (S. sanguinis and Candida glabrata) was introduced into the eppendorf tubes with implant assemblies and incubated for 14 days. At the end of 14 days the specimens from implant wells were taken and cultured and the formed colonies were counted using digital colony counter. The results obtained were tabulated and statistical analysis was done using Mann Whitney U test (SPSS V 20, USA).

The test revealed that the microbial leakage for Streptococcus sanguinis and Candida glabrata between Titanium and Zirconia abutments without sealant has no 
Table 4. To compare the microleakage at IAI between subgroups $2 \mathrm{AC}$ and $2 \mathrm{BC}$ for Candida glabrata with and without sealant

\begin{tabular}{|c|c|c|c|}
\hline & Subgroup 2 & $2 \mathrm{AC}$ (CFUs/ml) & Subgroup 2BC (CFUs/ml) \\
\hline Sample 1 & & $10^{8}$ & Growth inhibited \\
\hline Sample 2 & & $10^{8}$ & $2 \times 10^{2}$ \\
\hline Sample 3 & & $10^{8}$ & Growth inhibited \\
\hline Sample 4 & & $10^{8}$ & Growth inhibited \\
\hline Sample 5 & & $10^{8}$ & Growth inhibited \\
\hline Sample 6 & & $10^{8}$ & Growth inhibited \\
\hline Sample 7 & & $10^{8}$ & Growth inhibited \\
\hline Sample 8 & & $10^{8}$ & Growth inhibited \\
\hline Sample 9 & & $10^{8}$ & Growth inhibited \\
\hline Sample 10 & & $10^{8}$ & Growth inhibited \\
\hline Organism tested & Group 2 & Median & P-value \\
\hline Candida glabrata & \#Subgroup 2AC (without sealant) & 8.0000 & $0.002 *$ \\
\hline Candida glabrata & "Subgroup 2BC (with sealant) & 2.3010 & \\
\hline
\end{tabular}

\#Mann Whitney $U$ test to determine difference in microbial leakage for Candida glabrata between 2AC and 2BC.

The cell density of the inoculated polymicrobial suspension is $10^{8} \mathrm{CFUs} / \mathrm{ml}$.

*P-value<0.05: Statistically significant.

Subgroup 2AC: Zirconia abutments without sealant checked for Candida glabrata.

Subgroup 2BC: Zirconia abutments with sealant checked for Candida glabrata.

Table 5. Comparison of microleakage between group 1 (subgroup 1B) and group 2 (subgroup 2B) for Streptococcus sanguinis (Titanium and Zirconia abutments) with sealant

\begin{tabular}{ccc}
\hline & $\begin{array}{c}\text { Group } 1 \text { subgroup } \\
\text { 1BS (CFUs/ml) }\end{array}$ & $\begin{array}{c}\text { Group 2 subgroup } \\
\text { 2BS (CFUs/ml) }\end{array}$ \\
\hline Sample 1 & $2 \times 10^{2}$ & Growth inhibited \\
Sample 2 & Growth inhibited & $2 \times 10^{2}$ \\
Sample 3 & Growth inhibited & Growth inhibited \\
Sample 4 & Growth inhibited & Growth inhibited \\
Sample 5 & $3 \times 10^{2}$ & Growth inhibited \\
Sample 6 & Growth inhibited & Growth inhibited \\
Sample 7 & Growth inhibited & Growth inhibited \\
Sample 8 & Growth inhibited & Growth inhibited \\
Sample 10 & Growth inhibited & Growth inhibited \\
\hline
\end{tabular}

The cell density of the inoculated polymicrobial suspension is $10^{8} \mathrm{CFUs} / \mathrm{ml}$.

Subgroup 1BS: Titanium abutments with sealant checked for Streptococcus sanguinis.

Subgroup 2BS: Zirconia abutments with sealant checked for Streptococcus sanguinis.

statistically significant difference $(\mathrm{P}>0.05)$. On application of sealant both Titanium and Zirconia abutments showed statistically significant difference in microbial leakage when compared without application of sealant for both organisms $(\mathrm{P}<0.05)$ (Tables 1-4).

The test revealed that the microbial leakage for Streptococcus sanguinis between Titanium and Zirconia abutments has no statistically significant difference $(\mathrm{P}>0.05)$ (Table 5). The test revealed that the microbial leakage between Titanium and Zirconia abutments for
Table 6. Comparison of micro bialleakage between group 1 (subgroup 1B) and group 2 (subgroup 2B) for Candida glabrata (Titanium versus Zirconia abutments) with sealant

\begin{tabular}{ccc}
\hline & $\begin{array}{c}\text { Group 1 subgroup } \\
\text { 1BC }(\mathrm{CFUs} / \mathrm{ml})\end{array}$ & $\begin{array}{c}\text { Group 2 subgroup } \\
\text { 2BC }(\mathrm{CFUs} / \mathrm{ml})\end{array}$ \\
\hline Sample 1 & Growth inhibited & Growth inhibited \\
Sample 2 & Growth inhibited & $2 \times 10^{2}$ \\
Sample 3 & $3 \times 10^{2}$ & Growth inhibited \\
Sample 4 & Growth inhibited & Growth inhibited \\
Sample 5 & Growth inhibited & Growth inhibited \\
Sample 6 & Growth inhibited & Growth inhibited \\
Sample 7 & $2 \times 10^{2}$ & Growth inhibited \\
Sample 8 & Growth inhibited & Growth inhibited \\
Sample 9 & Growth inhibited & Growth inhibited \\
Sample 10 & Growth inhibited & Growth inhibited \\
\hline
\end{tabular}

The cell density of the inoculated polymicrobial suspension is $10^{8} \mathrm{CFUs} / \mathrm{ml}$.

Subgroup 1BC: Titanium abutments with sealant checked for Candida glabrata.

Subgroup 2BC: Zirconia abutments with sealant checked for Candida glabrata.

Candida glabrata has no statistically significant difference ( $>>0.05)$ (Table 6)

On comparison among Streptococcus sanguinis and Candida glabrata, the colony forming units formed in Titanium abutments -Titanium implant interface with sealant following microbial leakage shows statistically no significant difference $(\mathrm{P}>0.05)$. The colony forming units formed in Zirconia abutments -Titanium implant interface with sealant following microbial leakage shows statisti- 
Table 7. Comparision of microbial leakage titanium and Zirconia abutments with sealant using Mann Whitney $U$ test

\begin{tabular}{clc}
\hline Organisms tested & \multicolumn{1}{c}{ Groups } & \multicolumn{1}{c}{ P-value } \\
\hline Streptococcus sanguinis & Group 1 (Titanium abutments) 1BS & 0.480* \\
Streptococcus sanguinis & Group 2 (Zirconia abutments) 2BS & 1.000* \\
Candida glabrata & Group 1 (Titnaium abutments) 1BC & \\
Candida glabrata & Group 2 (Zirconia abutments) 2BC \\
\hline
\end{tabular}

*P-value >0.05: statistically no significant difference.

Subgroup 1BS: Titanium abutments with sealant checked for Streptococcus sanguinis.

Subgroup 2BS: Zirconia abutments with sealant checked for Streptococcus sanguinis.

Subgroup 1BC: Titanium abutments with sealant checked for Candida glabrata.

Subgroup 2BC: Zirconia abutments with sealant checked for Candida glabrata.

Table 8. Comparision of microbial leakage between Streptococcus sanguinis and Candida glabrata in Titanium and Zirconia abutments with sealant using Mann Whitney $U$ test

\begin{tabular}{ccc}
\hline Type of abutment & Organism & P-value \\
\hline Titanium abutments (Group1) & Streptococcus sanguinis & Candida glabrata \\
Zirconia abutments (Group 2) & Streptococcus sanguinis & Candida glabrata \\
& 1.000*
\end{tabular}

*P-value >0.05: statistically no significant difference.

cally no significant difference $(\mathrm{P}>0.05)$ (Table 7,8$)$.

\section{DISCUSSION}

Biofilm formation due to the accumulation of microorganisms at the implant abutment interface in two piece implants will lead to microbial leakage into the implant wells through the microgap between implant and abutment, thereby causing inflammation of the peri-implant tissues, which affects the success of osseointegrated implants in a long term ${ }^{9,12,14)}$.

It has been reported that bacteria found around implants from the oral cavity of patients with clinical signs of periimplantitis present a microbiota pattern similar to that of natural teeth affected with periodontitis ${ }^{12,35,36)}$.

In this study we have inoculated Streptococcus sanguinis and Candida glabrata to evaluate the microbial leakage at the implant abutment interface as the dimensions of these organisms are smaller, and can easily pass through the microgap in the implant abutment interface $^{9,12,13,37)}$. In studies without sealant application, these organisms were seen inside the implant wells following 14 days of incubation at 37 degree centigrade.

Candida glabrata is dimensionally smaller than $\mathrm{C}$. albicans. Silva et al. reported that C. glabrata exhibits a degree of hydrophobicity comparable with that of C. albicans, although only a few studies have evaluated the role and pathogenicity of $\mathrm{C}$. glabrata in the formation of biofilm on medical devices ${ }^{37}$. The ability of C. glabrata to enter and arrange a mixed biofilm in coaggregation with Streptococcus sanguinis in implant systems had been stated by Baggi et al. ${ }^{12}$. In this study we have evaluated Candida glabrata in Titanium implant systems with CAD/CAM Zirconia abutments. The existence of bacterial leakage is not surprising if one compares the diameter of oral microorganisms (less than $10 \mathrm{~mm}$ ) with the passive fit between implant components.

The present study analyzed the microbial contamination within the implant surfaces, in a manner similar to previous studies except for the use of CAD/CAM zirconia abutments ${ }^{8,21)}$. Quirynen et al. performed an in vitro study using only Branemark implant system to evaluate their resistance against bacterial penetration at implant-abutment interface ${ }^{9)}$.

Findings from similar in-vitro studies have documented that bacteria infiltration may occur both from an external source to the inner area of an implant and in reverse. This migration of bacteria is probably facilitated through the unavoidable presence of microgaps between the fixture and the abutment components of the as- 
sembled system ${ }^{3,8,11,21,28,38)}$. The larger the microgap, larger the bacterial accumulation, leading to periimplant pathology. Under clinical loading, these microgaps may be further widened when bending forces during function loosen the screw joint ${ }^{16,40)}$. The microgap between the implant and the abutment ranges from 0.1 to $5.6 \mu \mathrm{m}$. Scarano et al.have stated that microgap in screw retained implant-abutment system is critical for bacterial colonization and the microgap size will be much larger in vivo than seen in vitro ${ }^{3)}$.

Rotational freedom between the implant and the abutment is a critical factor related to the stability of the implant-abutment connection. The implant- abutment connection is most stable when the degree of rotational freedom is less than $2^{\circ}$, and significant torque loss occurs when the degree is greater than $5^{\circ}$. Anti-rotation design of the abutment can limit the rotational freedom, thereby maintaining the stability of the joint when the degree is greater than 5 degrees ${ }^{41}$. The parafunctions such as bruxism, excessive occlusal force, bad chewing habits, and others which might be risk factors of screw loosening, should cause concern as screw loosening will result in increase of microgap between abutment and implant, thereby increasing microleakage ${ }^{42}$. The antirotational property of internal hexagon connection in providing stability and preventing screw loosening under loaded conditions was proved in previous studies ${ }^{43,44)}$.

Attempts to minimize the bacterial leakage through the implant abutment interface have led to constant modifications of implant connection designs. In previous in vitro studies, evaluating the microleakage in different types of connections, it was found, in all cases, a much lesser degree of bacterial leakage in internal conical connections ${ }^{22,23,45-49)}$. A recent review of the literature reported that external hexagon implants had the greatest bacterial leakage, followed by internal trilobe, internal hexagon, and internal taper configuration. Internal Morse Cone conical connection Implants showed an absolute congruity without any microgaps between implant and abutment ${ }^{14,46,50-52)}$. In this study we have evaluated the microbial leakage using internal hexagon implants with Titanium and CAD/CAM milled Zirconia abutments.As stated by Quirynen and van Steenberghe, hermetic sealing is capable of causing the death of microorganisms ${ }^{9}$.
Motosfy, Zarbaksh concluded that the use of GapSeal decreased the microgap and microleakage in internal hex implant-abutment connection ${ }^{30,53)}$.

Nayak et al. proved that using a gel easily throughout the Implant abutment interface, leading to a better seal than the O-ring. Unlike the low viscosity gel, the O-ring's body prevents complete seating of the abutment. The rubber can deteriorate over time, which may increase leak$\operatorname{age}^{21)}$.

Podhorsky et al. concluded that usage of setting, non setting sealing agents and disinfectant agents reduced bacterial load inside the implant well. He also stated that setting compounds were difficult to remove and usage of greasy sealing agents has shown promising outcome preventing microleakage in his study ${ }^{33)}$.

Zekiy concluded that an antiseptic sealant and a nanocoated implant- abutment interface will provide better osseointegration and stability to the implants with better outcomes $^{31)}$.

In this study a new sealant (Viruseal, DSI, ISRAEL) was used which proved to be effective in controlling microbial leakage at both titanium and zirconia abutments. This sealant provides a reliable seal and fills the hollow spaces in the implants. It is a highly viscous silicone matrix which ensures a reliable sealing and prevents the ingress of organisms. The principle of this material is that as the place is already occupied, there will be no nutrition for vital activity of organism to grow and develop. The addition of thymol ensures better antifungal and antibacterial activity. The material did not get dried off, maintaining its viscocity and preventing formation of new microgaps. Thin silicone film effectively prevents adhesion of plaque on the supporting implants. The leakage without a sealing agent was probably due to the lack of complete wall-to-wall adaptation between abutment and implant ${ }^{34)}$.

The microbial leakage of Titanium abutments (Group 1) for Streptococcus sanguinis and Candida glabrata without sealant was found to be significantly higher than the Titanium abutments with sealant and the difference was found to be statistically significant $(\mathrm{P}<0.05)$. The microbial leakage of Zirconia abutments (Group 2) for Streptococcus sanguinis and Candida glabrata without sealant was found to be significantly higher than the Zirconia 
abutments with sealant and the difference was found to be statistically significant $(\mathrm{P}<0.05)$. In this present study, Mann Whitney $U$ test revealed that there was there was no significant differences $(\mathrm{P}>0.05)$ in microbial leakage for Streptococcus sanguinis and Candida glabrata, among the two abutment types. This explains that the new sealant was effective in exhibiting both antibacterial and antifungal effect, irrespective of the type of abutments used in the present study. Factor of film thickness of this material and its possible interference with machining tolerance of the implant system should be considered. Here, the new sealant effectively sealed the microgap as evidenced from the various results, but whether tolerance was affected is a question requiring further research and necessitates a continuation study.clinically, Viruseal doesn't have any seting time and forms effective seal around the microgap and can be easily removed with alcohol swab in case of abutment removal for any reason and can be reapplied again. distortion in plane of contact between implant and abutment may be considered stress reducing ${ }^{55)}$.

Therefore the null hypothesis was accepted. This present study had some limitations, Streptococcus sanguinis and Candida glabrata were the only two microorganisms considered whereas the oral cavity harbours many organisms. Only internal hexagon connection design was evaluated. The study was conducted under unloaded conditions, whereas masticatory loads are present in oral cavity. Future studies should evaluate the marginal sealing efficacy of this new sealant with other available sealants. long term studies are required to evaluate its efficacy and the need for reapplication of the sealant should also be evaluated.

\section{CONCLUSION}

The new sealant was effective in exhibiting both antibacterial and antifungal effect, irrespective of the type of abutments and type of organism used in the present study. The new sealant used in this study was effective in reducing microbial leakage.

\section{CLINICAL SIGNIFICANCE}

This new sealant can be used clinically with both Titanium and Zirconia abutments over Titanium implants.

\section{ORCID}

Hariharan Ramakrishnan, https:/ / orcid.org/0000-0003-4466-5744

\section{REFERENCES}

1. Bharate V, Kumar Y, Koli D, Pruthi G, Jain V. Effect of different abutment materials (zirconia or titanium) on the crestal bone height in 1 year. J Oral Biol Craniofac Res 2020;10:372-4.

2. Gou M, Chen H, Fu M, Wang H. Fracture of zirconia abutments in implant treatments: a systematic review. Implant Dent 2019;28:378-87.

3. Scarano A, Valbonetti L, Degidi M, Pecci R, Piattelli A, De Oliveira PS, et al. Implant-abutment contact surfaces and microgap measurements of different implant connections under 3-dimensional X-ray microtomography. Implant Dent 2016; 25:656-62.

4. Andreiotelli M, Wenz HJ, Kohal RJ. Are ceramic implants a viable alternative to titanium implants? A systematic literature review. Clin Oral Implants Res 2009;20:32-47.

5. Patil R. Zirconia versus titanium dental implants: A systematic review. J Dent Implant. 2015;5(1):39-42.

6. Hisbergues M, Vendeville S, Vendeville P. Zirconia: Established facts and perspectives for a biomaterial in dental implantology. J Biomed Mater Res B Appl Biomater 2009;88:519-29.

7. Carnovale F, Patini R, Penarrocha D, Muzzi M, Pistilli R, Canullo L. Measurement of gap between abutment and fixture in dental conical connection implants. A focused ion beam SEM observation. Med Oral Patol Oral Cir Bucal 2020;25:e449.70.

8. Quirynen M, Van Steenberghe D. Bacterial colonization of the internal part of two-stage implants. An in vivo study. Clin Oral Implants Res 1993;4:158-61.

9. Quirynen M, Bollen CM, Eyssen H, Van Steenberghe D. Microbial penetration along the implant components of the Brånemark system ${ }^{\circledR}$. An in vitro study. Clin Oral Implants Res 1994;5:239-44.

10. Abdelhamed MI, Galley JD, Bailey MT, Johnston WM, Holloway J, McGlumphy E, et al. Bidirectional microleakage around two types of abutments. Clin Implant Dent Relat Res 2015;17: e643-51.

11. Do Nascimento C, Barbosa RE, Issa JP, Watanabe E, Ito IY, Albuquerque RF Jr. Bacterial leakage along the implant-abutment interface of premachined or cast components. Int J Oral Maxillofac Surg 2008;37:177-80.

12. Baggi L, Di Girolamo M, Mirisola C, Calcaterra R. Microbiologi- 
cal evaluation of bacterial and mycotic seal in implant systems with different implant-abutment interfaces and closing torque values. Implant Dent 2013;22:344-50.

13. Aloise JP, Curcio R, Laporta MZ, Rossi L, da Silva AMÁ, Rapoport A. Microbial leakage through the implant-abutment interface of morse taper implants in vitro. Clin Oral Impl Res 21, 2010;328-35.

14. Koutouzis T, Wallet S, Calderon N, Lundgren T. Bacterial colonization of the implant-abutment interface using an in vitro dynamic loading model. J Periodontol 2011;82:613-8.

15. Broggini N, McManus LM, Hermann JS, Medina RU, Oates TW, Schenk RK, et al. Persistent acute inflammation at the implantabutment interface. J Dent Res 2003;82:232-7.

16. Liu Y, Wang J. Influences of microgap and micromotion of implant-abutment interface on marginal bone loss around implant neck. Arch Oral Biol 2017;83:153-60.

17. Baixe S, Fauxpoint G, Arntz Y, Etienne O. Microgap between zirconia abutments and titanium implants. Int J Oral Maxillofac Implants 2010;25:455-60.

18. Smith NA, Turkyilmaz I. Evaluation of the sealing capability of implants to titanium and zirconia abutments against Porphyromonas gingivalis, Prevotella intermedia, and Fusobacterium nucleatum under different screw torque values. J Prosthet Dent 2014;112:561-7.

19. Harder S, Dimaczek B, Açil Y, Terheyden H, Freitag-Wolf S, Kern M. Molecular leakage at implant-abutment connection -in vitro investigation of tightness of internal conical implant-abutment connections against endotoxin penetration. Clin Oral Investig 2010;14:427-32.

20. Grobecker-Karl T, Karl M. Correlation Between Micromotion and Gap Formation at the Implant-Abutment Interface. Int J Prosthodont 2017;30:150-2.

21. Nayak AG, Fernandes A, Kulkarni R, Ajantha GS, Lekha K, Nadiger R. Efficacy of antibacterial sealing gel and O-ring to prevent microleakage at the implant abutment interface: an in vitro study. J Oral Implantol 2014;40:11-4.

22. Black DL, Turkyilmaz I, Lien W, Chong $\mathrm{CH}$. Evaluation of the sealing capability of the internal conical connections of implants with titanium and zirconia abutments. J Contemp Dent Pract 2017;18:915-22.

23. Triveni VV, Jagadeesh KN, Parihar AS, Alduwayhi S, Annapoorneshwari S, Khalid FM, et al. Evaluation of microleakage and microgap of two different internal implant-abutment connections: an in vitro study. J Contemp Dent Pract 2020;21: 683-5

24. Mencio F, Papi P, Di Carlo S, Pompa G. Salivary bacterial leakage into implant- abutment connections: preliminary results of an in vitro study. Eur Rev Med Pharmacol Sci 2016;20: 2476-83.

25. de Sousa CA, Taborda MBB, Momesso GAC, Rocha EP, Dos Santos PH, Santiago-Júnior JF, et al. Materials sealing preventing biofilm formation in implant/abutment joints: which is the most effective? a systematic review and meta-analysis. J Oral Implantol 2020;46:163-71.

26. Tallarico M, Canullo L, Caneva M, Özcan M. Microbial colonization at the implant-abutment interface and its possible influ- ence on periimplantitis: A systematic review and meta-analysis. J Prosthodont Res 2017;61:233-41.

27. Hazan R, Que YA, Maura D, Rahme LG. A method for high throughput determination of viable bacteria cell counts in 96-well plates. BMC Microbiology 2012;12:1-7.

28. Duarte AR, Rossetti PH, Rossetti LM, Torres SA, Bonachela WC. In vitro sealing ability of two materials at five different implant abutment surfaces. J Periodontol 2006;77:1828-32.

29. Ozdiler A, Bakir-Topcuoglu N, Kulekci G, Isik-Ozkol G. Effects of taper angle and sealant agents on bacterial leakage along the implant-abutment interface: an in vitro study under loaded conditions. Int J Oral Maxillofac Implants 2018;33:1071-7.

30. Mostofy S, Jalalian, E, Valaie N, Mohtashamrad Z, Haeri A, Bitaraf, et al. Study of the effect of gapseal on microgap and microleakage in internal hex connection after cyclic loading. J Res Dentomaxillofac Sci 2019;4:36-42.

31. Zekiy AO, Makurdumyan DA, Matveeva EA, Bogatov EA, Kaliiants TV. Antiseptic sealant and a nanocoated implant abutment interface improve the results of dental implantation. Clin Implant Dent Relat Res 2019;21:938-45.

32. Keedi CB, Marques AD, Rodrigues VA, Avila-Campos MJ, Tortamano P. Efficacy of a Polyglycol Dimethacrylate-Based Adhesive in Sealing the Implant- Abutment Interface. Implant dent 2019;28:265-71.

33. Podhorsky A, Biscoping S, Rehmann P, Streckbein P, Domann $E$, Woestmann B. Transfer of bacteria into the internal cavity of dental implants after application of disinfectant or sealant agents in vitro. Int J Oral Maxillofac Implants 2016;31:563-70.

34. Dental Solutions Israel Ltd. Evaluation of sealing between abutment and inner connection of dental implant: microgaps between implant and abutment. https://dsisrael.com, Cited Feb 3rd 2021.

35. Shahabouee M, Rismanchian M, Yaghini J, Babashahi A, Badrian H, Goroohi H. Microflora around teeth and dental implants. J. Dent. Res 2012;9:215-20.

36. Grover HS, Shukla S. Microbiology of dental implant: a review of literature. Int J Oral Implant Clin 2012;3:43-6.

37. Silva S, Pires P, Monteiro DR, Negri M, Gorup LF, Camargo ER, et al. The effect of silver nanoparticles and nystatin on mixed biofilms of Candida glabrata and Candida albicans on acrylic. Med Mycol 2013;51:178-84.

38. Jansen VK, Conrads G, Richter EJ. Microbial leakage and marginal fit of the implant-abutment interface. Int J Oral Maxillofac Implants 1997;12:527-40.

39. Traversy MC, Birek P. Fluid and microbial leakage of implantabutment assembly in vitro. J Dent Res 1992;71:754-7.

40. Karl M, Taylor TD. Parameters determining micromotion at the implant-abutment interface. Int J Oral Maxillofac Implants 2014;29:1338-47.

41. Huang $Y$, Wang J. Mechanism of and factors associated with the loosening of the implant abutment screw: a review. J Esthet Restor Dent 2019;31:338-45.

42. Sadowsky SJ. Occlusal overload with dental implants: a review. Int J Implant Dent 2019;5:1-5.

43. Khraisat A, Hashimoto A, Nomura S, Miyakawa O. Effect of lateral cyclic loading on abutment screw loosening of an external 
hexagon implant system. J Prosthet Dent 2004;91:326-34.

44. Yao KT, Kao HC, Cheng CK, Fang HW, Yip SW, Hsu ML. The effect of clockwise and counterclockwise twisting moments on abutment screw loosening. Clin Oral Implants Res 2012;23: 1181-6.

45. Passos SP, Gressler May L, Faria R, Özcan M, Bottino MA. Implant-abutment gap versus microbial colonization: Clinical significance based on a literature review. J Biomed Mater Res B Appl Biomater 2013;101:1321-8.

46. Silva-Neto JP, Prudente MS, Carneiro Tde A, Nóbilo MA, Penatti MP, Neves FD. Micro-leakage at the implant-abutment interface with different tightening torques in vitro. J Appl Oral Sci 2012;20:581-7.

47. Tesmer M, Wallet S, Koutouzis T, Lundgren T. Bacterial colonization of the dental implant fixture-abutment interface: an in vitro study. J Periodontol 2009;80:1991-7.

48. Gherlone EF, Capparé P, Pasciuta R, Grusovin MG, Mancini N, Burioni R. Evaluation of resistance against bacterial microleakage of a new conical implant-abutment connection versus conventional connections: an in vitro study. New Microbiol 2016;39:49-56.

49. Şen N, Şermet IB, Gürler N. Sealing capability and marginal fit of titanium versus zirconia abutments with different connection designs. J Adv Prosthodont 2019;11:105-11
50. Tripodi D, D'Ercole S, laculli F, Piattelli A, Perrotti V, lezzi G. Degree of bacterial microleakage at the implant-abutment junction in Cone Morse tapered implants under loaded and unloaded conditions. J Appl Biomater Funct Mater 2015;13: 367-71.

51. Siadat H, Najafi H, Alikhasi M, Falahi B, Beyabanaki E, Zayeri F. Effect of lateral oblique cyclic loading on microleakage and screw loosening of implants with different connections. J Dent Res Dent Clin Dent Prospects 2018;12:183-9.

52. Othman A, Mandlbauer L, Alevizakos V, Stoetzer M. Experimental investigation of the influence of chlorhexidine gel on the implant-abutment- connection. Research Square 2020. PPR: PPR148612

53. Zarbakhsh A, Mazaheri Tehrani A, Shamshirgar F, Khosroshahi H. Effect of GapSeal ${ }^{\circledR}$ as a sealing material on microgap and microleakage at external hexagon implant connections following cyclic loading: an in vitro study. J Res Dentomaxillofac Sci 2018;3:42-8.

54. Ferreira C, Costa B, Zanardi PR, Sesma N, Laganá DC. Sealing properties on the implant-abutment interface of a flowable silicone: an in vitro study. J Clin Dent Res 2016;13:61-7

55. Tsun Ma, Nicholls JI, Rubenstein JE. Tolerance measurements of various implant components. Int J Oral Maxillofac Implants 1997;12:371-5. 